\title{
Identificación inmunohistoquímica de las células productoras de somatostatina y polipéptido pancreático en páncreas de alpacas (Vicugna pacos)
}

\author{
IMMUNOHISTOCHEMICAL IDENTIFICATION OF SOMATOSTATIN AND PANCREATIC POLYPEPTIDE \\ PRODUCING CELLS IN PANCREAS OF ALPACAS (Vicugna pacos)
}

\author{
Nicanor Suni P. ${ }^{1}$, Miluska Navarrete Z. ${ }^{1,3}$, Nieves Sandoval C. ${ }^{2}$, \\ Francisco Santos R. ${ }^{1}$, Alexander Chávez R. ${ }^{1}$, Alberto Sato S. ${ }^{1}$
}

\section{RESUMEN}

El estudio tuvo por finalidad identificar y evaluar las células gamma (PP) y delta en páncreas de alpacas mediante inmunohistoquímica (IHQ). Las muestras se obtuvieron de 30 alpacas de la sierra sur del Perú (crías, jóvenes y adultas). Se utilizaron cortes histológicos de $5 \mu \mathrm{m}$ de espesor ( 3 por lóbulo y 2 del cuerpo). Se usó un kit comercial de IHQ y anticuerpos policlonales (anti-PP y anti-SSTR3) para identificar las células PP y delta, así como muestras de páncreas de rata como controles positivos. La intensidad de la marcación se clasificó cualitativamente entre 0 (sin marcación) hasta 3 (marcación fuerte). Las células PP estaban presentes en todos los grupos etarios, principalmente en el cuerpo y lóbulo derecho del páncreas, observándose principalmente en la periferia y zona intermedia de los islotes con una marcación media y fuerte. Las células delta estaban presentes en ambos lóbulos hasta los 4 meses de edad, sin observarse en juveniles ni en adultos. Las células delta se observaron principalmente en la periferia de los islotes con una marcación leve.

Palabras clave: alpaca; polipéptido pancreático; somatostatina; páncreas; inmunohistoquímica

\section{Abstract}

The aim of this study was to identify and evaluate gamma (PP) and delta cells in alpaca pancreas by immunohistochemistry (IHC). Samples were obtained from 30 alpacas from the southern highlands of Peru (crías, juveniles and adults). Histological sections of

\footnotetext{
${ }^{1}$ Laboratorio de Anatomía Animal y Fauna Silvestre, ${ }^{2}$ Laboratorio de Histología, Embriología y Patología Veterinaria, Facultad de Medicina Veterinaria, Universidad Nacional Mayor de San Marcos, Lima, Perú

${ }^{3}$ E-mail: mnavarretez@unmsm.edu.pe
}

Recibido: 25 de junio de 2017

Aceptado para publicación: 10 de noviembre de 2017 
$5 \mu \mathrm{m}$ thickness ( 3 per lobe and 2 of the body) were used. A commercial kit of IHC and polyclonal antibodies (anti-PP and anti-SSTR3) were used to identify PP and delta cells. Rat pancreas samples were used as positive controls. The intensity of the marking was qualitatively classified between 0 (no marking) and 3 (strong marking). PP cells were present in all age groups, mainly in the body and right lobe of the pancreas, being observed mainly in the periphery and intermediate zone of the islets with a medium and strong marking. Delta cells were present in both lobes until 4 months of age, without being observed in juveniles or adults. Delta cells were observed mainly on the periphery of the islets with a light marking.

Key words: alpaca; pancreatic polypeptide; somatostatin; pancreas; immunohistochemistry

\section{INTRODUCCIÓN}

La alpaca (Vicugna pacos) es la especie de mayor difusión de los camélidos sudamericanos, y se le cría en extensas áreas de pastos naturales en las zonas altoandinas, donde no es posible el desarrollo de la agricultura y la crianza exitosa de otras especies de animales domésticos. Las alpacas convierten con eficiencia la vegetación nativa de estos ambientes en carne y fibra de alta calidad (Quispe et al., 2009). La estructura de las vísceras y glándulas anexas del aparato digestivo de esta especie muestra diferencia morfológica y funcional con relación a otros rumiantes, especialmente a los bovinos.

La descripción macroscópica del páncreas ha sido documentada (Navarrete y Sato, 2010; Chávez et al., 2015; Panesi, 2016). A pesar de ello, se dispone de escasos trabajos referentes a las características de la histología del páncreas endocrino de la alpaca, quién presenta valores de glucosa elevados en comparación a los bovinos, ovinos y caprinos, además de presentar resistencia a la insulina sin desarrollar las complicaciones de cuadros clínicos de diabetes.

El conocimiento de la anatomía microscópica de los islotes de Langerhans es de fundamental importancia para la evaluación de los principios generales de la regulación de la secreción endocrina de los islotes pancreáticos en los mamíferos en general y, específicamente, de la alpaca. La presencia de somatostatina (SST) se ha descrito en diferentes zonas del sistema nervioso central (SNC), así como en numerosos tejidos periféricos, incluyendo el páncreas (Chanclón, 2013). Estudios in vitro indican que el polipéptido pancreático (PP) estimula la secreción enzimática, lo cual señalaría una posible acción paracrina en las células acinosas y ductales (Gutiérrez, 1988).

La técnica de inmunohistoquímica (IHQ) permite la identificación, sobre muestras tisulares o citológicas, de determinados antigénicos característicos de cada tipo celular, que son importantes en los diferentes procesos celulares, tales como diferenciación y función celular. La aplicación directa de anticuerpos policlonales o monoclonales sobre secciones tisulares permite la localización microanatómica de su expresión y su correlación con los parámetros morfológicos, aumentando la sensibilidad y especificidad del estudio y proporcionando información adicional esencial (Yang et al., 2011).

La IHQ fue empleada en el presente estudio para la identificación del os tipos ceIulares del ta y PP, objetivo de este estudio, debido a la especificidad que tienen por la reacción antígeno-anticuerpo con lashormonas buscadas. Antes dela adopción dela técnica de IHQ setuvo dificul tades paralaidentificación de los componentes cel ulares delos 
islotes, llegando incluso a encontrarse algunos de ellos cuyas células alfa y beta no se coloreaban $y$, que se denominaron en ese momento, como «third cell type» (Baskin, 2015). No obstante, la adopción de la técnica de IHQ ha permitido el desarrollo de trabajos de identificación de estos tipos celulares en múltiples especies. Por otro lado, debe indicarse que también se utiliza la inmunofluorescencia para su identificación (Chuan et al., 2015).

El presente estudio tuvo como objetivo brindar información básica de la ubicación y presencia de las células encargadas de la producción de somatostatina y el polipéptido pancreático para posteriores estudios sobre la fisiología endocrina del páncreas en la alpaca.

\section{Materiales Y Métodos}

\section{Animales}

Se emplearon 30 páncreas de alpacas Huacaya de las provincias de Canchis en la región Cusco y de Melgar en la región Puno, Perú. Se utilizaron cinco animales por grupo etario: recién nacidos, 1-2 semanas, 1 mes, 4 meses, 1-2 años y adultos (mayores de 2 años). El estudio tuvo la aprobación del Comité de Ética y Bienestar Animal de la Facultad de Medicina Veterinaria de la Universidad Nacional Mayor de San Marcos (Constancia 2017-002-UNMSM).

\section{Colección de Muestras}

Los animales fueron obtenidos de comunidades alpaqueras, ya sea por descarte fenotípico o por estar destinadas al camal. Para el sacrificio, se aplicó pentobarbital sódico como eutanásico, vía endovenosa en sobredosis a razón de $10 \mathrm{mg} / \mathrm{kg}$. Luego, se realizó una incisión en la superficie ventrolateral del tercio medio del cuello para exponer la vena yugular y arteria carótida para realizar el desangrado.
Se colectaron las muestras de páncreas y se conservaron en formaldehido tamponado al $10 \%$, para su transporte al Laboratorio de Anatomía Animal de la Facultad de Medicina Veterinaria de la Universidad Nacional Mayor de San Marcos, en Lima. Allí se procedió a la disección y separación de las porciones según la zona del órgano.

Cada páncreas fue dividido en ocho segmentos: extremo del lóbulo izquierdo, medio del lóbulo izquierdo, base del lóbulo izquierdo, extremo del lóbulo derecho, medio del lóbulo derecho, base del lóbulo derecho, extremo del cuerpo y base del cuerpo. De cada segmento se tomó una sección transversal de $3 \mathrm{~mm}$ de grosor, que incluía tanto la zona cortical como central del páncreas, para su inclusión en parafina. Una vez obtenidos los bloques parafinados, se realizaron cortes de $5 \mu \mathrm{m}$ de espesor y se procedió al montaje en láminas positivadas (Item 1354W - Globe Scientific Inc).

\section{Técnica de Inmunohistoquímica (IHQ)}

Se utilizó la técnica de IHQ con los anticuerpos y reactivos indicados en los cuadros 1 y 2 , siguiendo las especificaciones de los fabricantes para la identificación de células delta y PP en cortes histológicos. Asimismo, la técnica de IHQ se realizó siguiendo el protocolo de inmunohistoquímica $\mathrm{ABC}$ (Zanuzzi, 2010) estandarizado, con la diferencia en el tiempo de revelado empleando el cromógeno 3,3'-diaminobenzidine (DAB) que fue de 15 min la marcación para el polipéptido pancreático y de $20 \mathrm{~min}$ en el caso de la somatostatina.

Como control positivo se utilizó páncreas de rata adulta, tanto para la detección de somatostatina como de polipéptido pancreático (Elayat et al., 1995).

\section{Lectura de Láminas}

La lectura de las láminas se realizó con un microscopio trinocular AmScope M-370 (EEUU), registrándose los hallazgos con una cámara digital para microscopio (AmScope 
Cuadro 1. Anticuerpos utilizados para la IHQ en islotes endocrinos pancreáticos

\begin{tabular}{llll}
\hline $\begin{array}{l}\text { Anticuerpo } \\
\text { (tipo) }\end{array}$ & Huésped Fuente Dilución \\
\hline $\begin{array}{l}\text { Anti-Pancreatic } \\
\begin{array}{l}\text { Polypeptide. } \\
\text { (policlonal) }\end{array}\end{array}$ & Conejo & Bovino & $1: 500$ \\
$\begin{array}{l}\text { Anti-SSTR3. } \\
\text { (policlonal) }\end{array}$ & Conejo Humano & $1: 500$ \\
\hline
\end{tabular}

Fuente: US Biological Life Sciences

Cuadro 2. Reactivos utilizados para la técnica de inmunohistoquímica (IHQ) en islotes endocrinos pancreáticos

\begin{tabular}{ll}
\hline Reactivos & Dilución óptima \\
\hline ImmPACT DAB & $\begin{array}{l}30 \mu 1 \text { de } \\
\text { cromógeno en } 1 \mathrm{ml} \\
\text { peroxidase substrate }\end{array}$ \\
Vectastain ABC kit & Listo para su uso \\
\hline
\end{tabular}

Fuente: Vector Laboratories (SA)

FMA050). El conteo de islotes totales y con marcación positiva se realizó con ocular de $10 \mathrm{X}$ y objetivo de $10 \mathrm{X}$, mientras que el registro de los hallazgos se realizó con la cámara FMA050 (con una resolución de 8 MP) y con un objetivo de 40X. El programa utilizado para el registro de las imágenes fue de la misma casa matriz (AmScope).

Se contabilizó el número de islotes totales hallados en cada lámina y el número de islotes que presentaron marcación positiva a la hormona estudiada para hallar la proporción de islotes con presencia de la citada hormona. Para evitar el conteo repetido de los islotes se hizo movimientos en zigzag con la lámina. Se consideró marcación positiva a aquellas células que se tiñeron de un color dorado (desde dorado claro hasta marrón oscuro, debido a la reacción entre los anticuerpos y el cromógeno revelador). La intensidad de la marcación se clasificó cualitativamente como 0 : sin marcación, 1 : marcación leve, 2: marcación media y 3: marcación fuerte. Se realizó la comparación de los resultados hallados y se observaron las variaciones que podían presentarse entre las secciones del páncreas y los grupos etarios.

\section{Resultados}

Los islotes presentaron diversas formas y tamaños, con número variable de células y en diferentes proporciones de tipos celulares. Los islotes de Langerhans se observaron como masas irregulares de células, lo cual difiere de la información conocida en otras especies domésticas.

Los islotes fueron vistos como áreas compactas de células pálidas, infiltrados con una gran cantidad de vasos sanguíneos capilares y rodeados de tejido pancreático exocrino más oscuro. Con regular frecuencia se observaron lo que parecían ser células endocrinas individuales dentro del páncreas exocrino. Las células de los islotes estaban dispuestas de manera tal que sugerían grupos o cordones en una perspectiva tridimensional.

\section{Células PP}

Las proporciones de estas células endocrinas variaron entre islotes, incluso entre islotes ubicados en un mismo campo de observación, pero siempre en mayor concentración que las células delta.

Las células PP se presentaron en forma individual o en grupos en la zona periférica del islote, en ocasiones formando una corona en torno a las células centrales, mostrando una marcación en grado 2 o 3. Estuvieron presentes en mayor concentración en el cuerpo y lóbulo derecho de los animales estudiados, especialmente en el caso de animales juveniles y adultos (Figura 1). La marcación 
Cuadro 3. Islotes de Langerhans en páncreas de alpacas con marcaje positivo a células productoras de polipéptido pancreático, expresado en porcentaje, según grupo etario

\begin{tabular}{lcccccc}
\hline $\begin{array}{l}\text { Sección } \\
\text { pancreática }\end{array}$ & $\begin{array}{c}\text { Recién } \\
\text { nacidos }\end{array}$ & $\begin{array}{c}1-2 \\
\text { semanas }\end{array}$ & 1 mes & 4 meses & $\begin{array}{c}\text { Juvenil } \\
(1-2 \\
\text { años })\end{array}$ & $\begin{array}{c}\text { Adultas } \\
(>2 \text { años })\end{array}$ \\
\hline Lóbulo izquierdo & 90 & 40 & 36 & 90 & 28 & 36 \\
Lóbulo derecho & 41 & 59 & 63 & 83 & 50 & 69 \\
Cuerpo & 63 & 90 & 91 & 100 & 55 & 43 \\
\hline
\end{tabular}

Cuadro 4. Hallazgos de islotes de Langerhans con marcaje positivo a células delta productoras de somatostatina

\begin{tabular}{lcccccc}
\hline $\begin{array}{l}\text { Sección } \\
\text { pancreática }\end{array}$ & $\begin{array}{c}\text { Recién } \\
\text { nacidos }\end{array}$ & $\begin{array}{c}1-2 \\
\text { semanas }\end{array}$ & 1 mes & 4 meses & $\begin{array}{c}\text { Juvenil } \\
(1-2 \\
\text { años })\end{array}$ & $\begin{array}{c}\text { Adultas } \\
(>2 \text { años })\end{array}$ \\
\hline Lóbulo izquierdo & 25 & 25 & 13 & 22 & 5 & 0 \\
Lóbulo derecho & 3 & 23 & 32 & 30 & 5 & 0 \\
Cuerpo & 0 & 3 & 25 & 5 & 0 & 0 \\
\hline
\end{tabular}

positiva de islotes con presencia de células conteniendo PP en los grupos etarios se muestra en el Cuadro 3.

Se pudo observar una mayor presencia de células PP en el lóbulo derecho del páncreas, así como una presencia constante en el cuerpo del mismo, siempre prevaleciendo en una ubicación periférica dentro del islote endocrino. También se pudo observar la presencia de los denominados «Islotes ricos en células $\mathrm{PP}$ » en diversas áreas del tejido pancreático (Figura 2).

\section{Células Delta}

La presencia de células delta, productoras de somatostatina, fue escasa en la mayoría de individuos y secciones (Cuadro 4). Estas células fueron observadas en animales recién nacidos y hasta de 4 meses, con mar- cación positiva a somatostatina con una coloración de baja intensidad (grado 1). No se encontraron en alpacas adultas.

Se observó una mayor presentación de células delta en los lóbulos, tanto derecho como izquierdo, que en el cuerpo del páncreas en animales de menor edad, posiblemente debido a que estos individuos se encuentran en pleno crecimiento y, por lo tanto, con mayor fluctuación de somatostatina y sus antagonistas (Figura 3). Las células delta, en animales juveniles y adultos se encontraban con presencia mínima.

Las células delta tenían una ubicación periférica dentro de los islotes endocrinos en animales recién nacidos hasta juveniles, aunque también se observó células en posición central en animales de 1 semana hasta de 4 meses. 

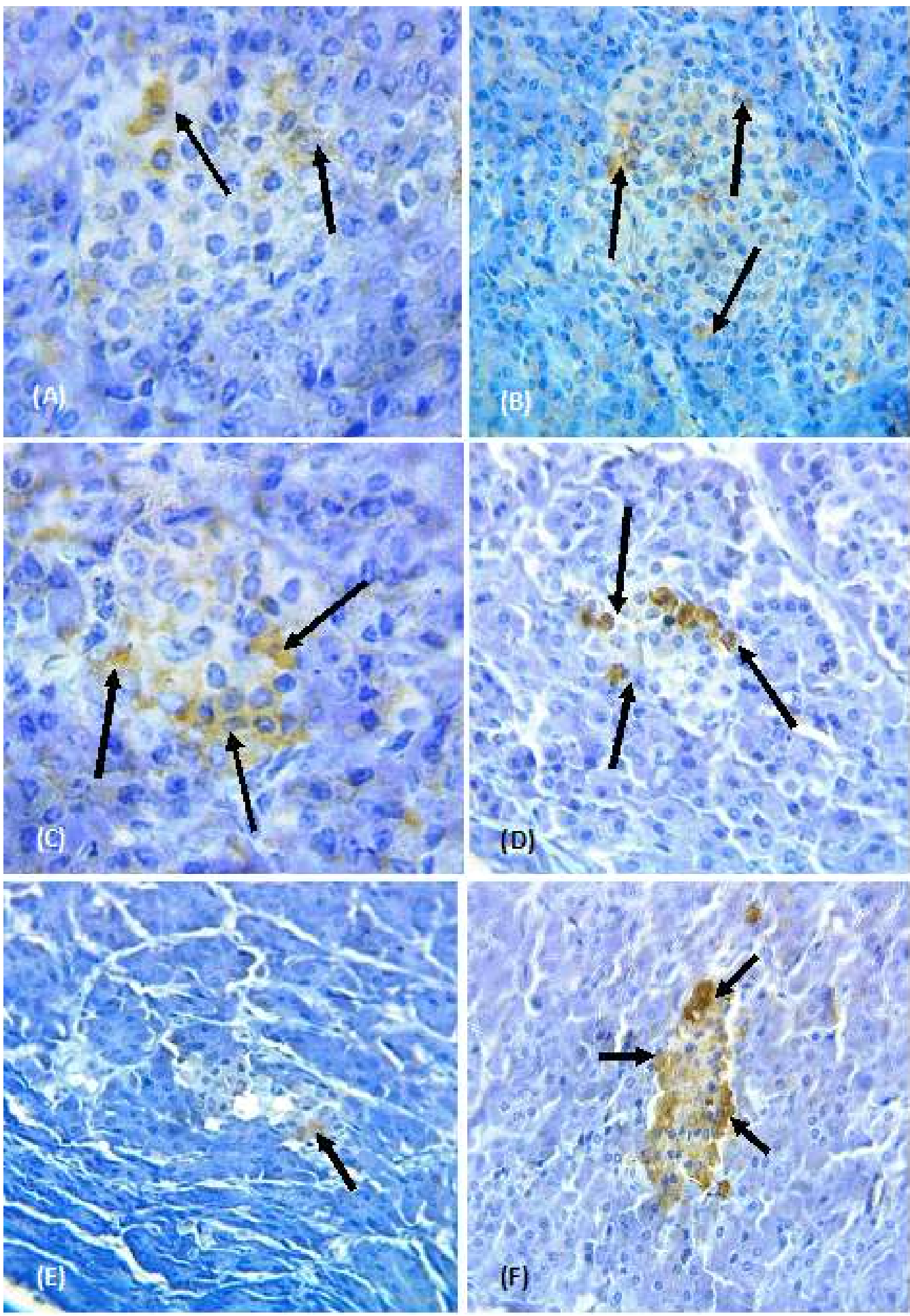

Figura 1. Islotes de Langerhans en páncreas de alpacas con marcación positiva a presencia de células células productoras de polipéptido pancreático (IHQ, 400X). A: en lóbulo izquierdo en recién nacida. B: en el cuerpo en cría de 1-2 semanas. C: en el cuerpo de cría de 1 mes. D: en el lóbulo izquierdo de cría de 4 meses. E: en el cuerpo de alpaca joven de 1-2 años. F: Islote donde se puede observar la presencia de los denominados «Islotes ricos en células PP» en el lóbulo derecho de alpaca adulta 


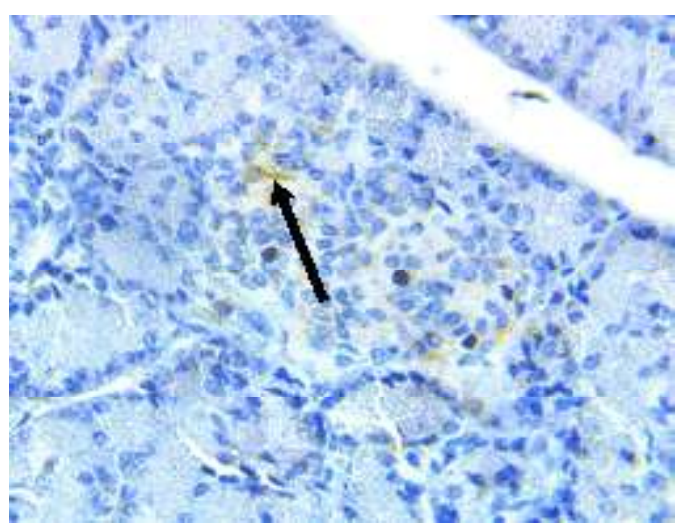

Figura 2. Islote con marcación positiva a presencia de células delta en lóbulo izquierdo del páncreas de alpaca recién nacida (IHQ, 400X)

\section{Discusión}

Diversos estudios indican una variación en la presencia de las células productoras de somatostatina y polipéptido pancreático, así como en la distribución de las mismas en las diferentes áreas de los islotes de Langerhans del páncreas. En el caso del camello y del caballo tienen una mayor proporción de células beta y alfa (productoras de insulina y glucagón, respectivamente) que de células delta y PP (productoras de somatostatina y polipéptido pancreático, respectivamente), a diferencia de los vacunos donde las células beta predominan seguidas de las células PP, y en menor proporción las células delta y alfa (Hafez et al., 2015).

En la distribución de las células PP y delta en el islote endocrino, la mayoría se localiza en la periferia de los islotes en el caso de bovinos (Bonner-Wier y Like, 1980), caballos (Helmstaedter et al., 1976; Furuoka et al., 1989) y camellos (Al Ani, 1987). Otro estudio en camellos señala que su localización puede ser periférica o central (Ali y Masaad, 2007), con bastante semejanza a lo encontrado en el presente trabajo. Estudios recientes confirman que las células delta y células PP se localizan en todo el islote, tanto en camellos como en caballos, mientras que su distribución es periférica en el caso de los bovinos (Hafez et al., 2015).

Los islotes endocrinos en bovinos (Bos taurus) presentan una masa central de células beta, que comprenden la mayor población de células endocrinas primarias. Esta masa central está parcialmente rodeada por un manto de células alfa, aunque las células beta a veces se extienden hacia la periferia. Las células delta también están localizadas principalmente en la periferia del islote, extendiéndose a veces en la parte central, mientras que las células PP están situadas en una zona densa en la periferia del islote (BonnerWier y Like, 1980). Asimismo, se han reportado islotes con número alto de células alfa $\mathrm{e}$ islotes con alto número de células PP (y células beta); además, que se tiene más células delta en islotes con proporciones más altas de células alfa, y más células PP en islotes con proporciones más bajas de células alfa (Hiratsuka et al., 1996).

En camellos dromedarios (Camelus dromedarius), el tipo celular prevaleciente son las células beta y se encuentran en el centro de los islotes. Están rodeados por un manto de células alfa con un pequeño número de células delta. Las células PP se encuentran dentro del islote, así como en el tejido exocrino. Las células endocrinas se encuentran en cantidades y proporciones aproximadamente iguales en las diversas regiones del páncreas (Khatim et al., 1985; Zghair, 2016).

En caballos (Equus ferus caballus), las células beta comprenden la mayoría de la población de células endocrinas de los islotes y forman una capa casi continua alrededor del centro del islote. Se observa una masa central de células alfa, casi enteramente rodeada por un manto de células beta (Helmstaedter et al., 1976; Ito et al., 1978). Las células delta se encuentran en forma discontinua en la periferia de los islotes, ya sea en la periferia con las células beta o entre los grupos de células alfa y beta 

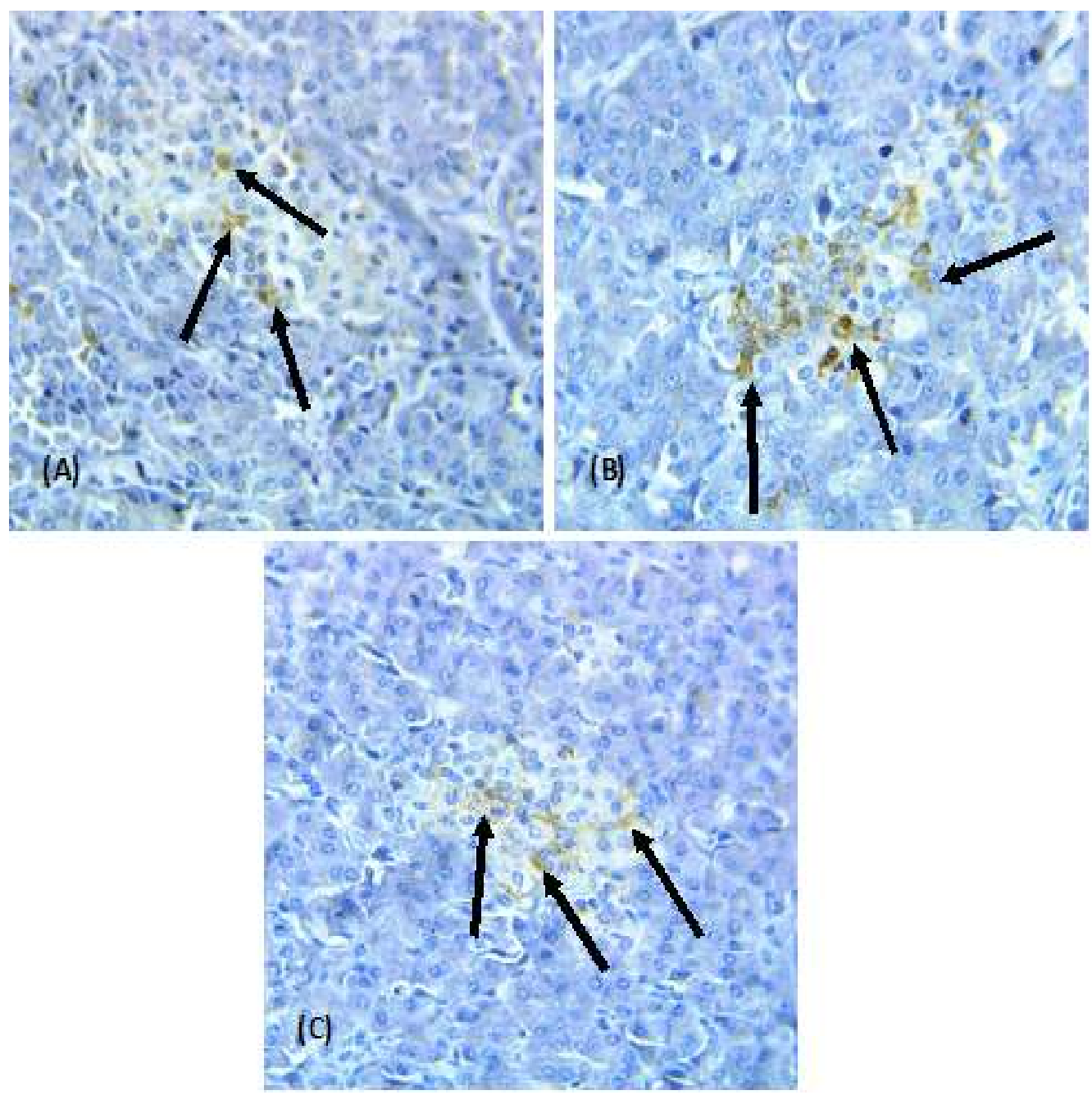

Figura 3. Islotes de Langerhans en páncreas de alpaca con marcación positiva a presencia de células delta (IHQ, 400X). A: en el cuerpo de cría entre 1-2 semanas. B: en el lóbulo derecho de cría de 1 mes. C: en el lóbulo izquierdo de cría de 4 meses

(Forssmann, 1976). Las células PP también se encuentran esporádicamente en la periferia (Furuoka et al., 1989).

En cabras (Capra aegagrus hircus), las células beta son la población primaria de células endocrinas. Estas células están localizadas centralmente, mientras que las células alfa se localizan típicamente en la periferia. Las células delta están dispuestas en gru- pos que corren a través del islote, y están presentes tanto en el interior como en la periferia. Las células PP están situadas en grupos densos dentro del islote (Reddy et al., 1985).

En un trabajo sobre el desarrollo de células endocrinas fetales y la formación de islotes en ovinos domésticos (Ovis aries) gestantes, Reddy et al. (1988) encontró que 
las células PP son raras y que solo se encuentran como células individuales a los 40 días de gestación, aumentando en número con el desarrollo fetal. Similar situación fue indicada para el caso de las células delta.

Se ha reportado, en múltiples especies, la presencia de islotes en los que prevalecen un tipo de células en particular. Por ejemplo, los denominados islotes pancreáticos ricos en células alfa e islotes pancreáticos ricos en células PP, que se encuentran en una relación inversamente proporcional, en el caso de caninos (Muranishi et al., 1999), marsupiales, monotremas y aves (Chuan et al., 2015). En humanos se ha determinado que un área específica del páncreas, menor al $2 \%$ del área total, es donde se encuentra la mayor concentración de islotes ricos en células PP (Wang et al., 2013).

La variación existente en la proporción de células PP y delta puede estar influenciada por el estado fisiológico individual de cada animal (sexo, gestación, edad). Algunos estudios informan que nuevas células surgen por neogénesis o diferenciación de las células endocrinas del islote del epitelio ductal o por la replicación de las células de islotes existentes (Finegood et al., 1995; Montanya et al., 2000; Wang et al., 2001). Estudios en ovejas Mehraban determinaron que los islotes de Langerhans presentan un mayor tamaño en recién nacidos y disminuían de tamaño con la edad (Mansouri et al., 2006).

Steiner et al. (2010) y Kim et al. (2009), en estudios con una gran variedad de especies encontraron no solo una gran variación en la composición de los islotes entre especies, sino también dentro de la misma especie. Asimismo, por efecto de la gestación, obesidad y diabetes; de allí que se puede inferir que un estado fisiológico en particular puede desencadenar el desarrollo y proliferación de islotes endocrinos compuestos por un tipo de células según el requerimiento fisiológico del individuo.

\section{Conclusiones}

- Las células PP se presentan en el páncreas de la alpaca, especialmente en el cuerpo y lóbulo derecho, localizándose en la periferia de los islotes endocrinos.

- Se encontró la presencia de islotes donde predominan las células PP, similares a los denominados «islotes ricos en células $\mathrm{PP}$ » encontrados en otras especies.

- Las células delta, secretoras de somatostatina, fueron observadas en el páncreas de la alpaca desde los primeros meses de vida, disminuyendo su presencia con el avance de la edad de los animales. Se les encuentra en ambos lóbulos del páncreas endocrino, tanto en la periferia como en la zona central de los islotes endocrinos.

\section{Agradecimiento}

Los autores manifiestan su agradecimiento al FONDECYT CONCYTEC, Convenio $097-2014$, por el financiamiento del estudio.

\section{Literatura Citada}

1. Ali G, Masaad GAM. 2007. A comparative morphological study on the pancreas of the dromedary and the donkey. MSc Thesis. Sudan: University of Khartoum. $160 \mathrm{p}$.

2. Al Ani MI. 1987. Light microscopy of the camel (Camelus dromedaries) islets of Langerhans. J Sugar Beet Res 18(1): 75-80.

3. Baskin DG. 2015. A historical perspective on the identification of cell types in pancreatic islets of Langerhans by staining and histochemical techniques. J Histochem Cytochem 63: 543-558. doi: 10.1369/0022155415589119

4. Bonner-Weir S, Like AA. 1980. A dual population of islets of Langerhans in bovine pancreas. Cell Tissue Res 206: 157-170. 
5. Chanclón B. 2013. Papel de la somatostatina, cortistatina y ghrelina en la desregulación celular y molecular del páncreas endocrino en situaciones metabólicas normales y extremas como la obesidad y la diabetes. Tesis Doctoral. España: Universidad de Córdoba. $211 \mathrm{p}$.

6. Chávez A, Panesi G, Sato A, Santos F, Navarrete M. 2015. Anatomía macroscópica del páncreas de la alpaca adulta (Vicugna pacos). En: VII Congreso Mundial de Camélidos Sudamericanos. Puno, Perú.

7. Chuan H, Myers MA, Forbes BE, Greutzner F. 2015. Immunohistochemical analysis of pancreatic islets of platypus (Ornithorhynchus anatinus) and echidna (Tachyglossus aculeatus ssp). J Anat 226: 373-80. doi: 10.1111/joa.12279

8. Elayat AA, El-Naggar MM, Tahir M. 1995. An immunocytochemical and morphometric study of the rat pancreatic islets. J Anat 186: 629-637.

9. Finegood D, Scaglia L, Bonner-Weir $S .1995$. Dynamics of $\beta$-cell mass in the growing rat pancreas: estimation with a simple mathematical model. Diabetes 44: 249-256. doi: 10.2337/diab.44.3.249

10. Forssmann A. 1976. The ultrastructure of the cell types in the endocrine pancreas of the horse. Cell Tiss Res 167: 179-195.

11. Furuoka H, Ito H, Hamada M, Suwa T, Satoh H, Itakura C. 1989. Immunocytochemical component of endocrine cells in pancreatic islets of horses. Nihon Juigaku Zasshi 51:35-43.

12. Gutierrez O. 1988. Péptidos reguladores del sistema digestivo. Acta Med Colomb 13: 254-258.

13. Hafez S, Zaghloul D, Caceci T. 2015. Inmunohistochemical identification of the endocrine cells in the pancreatic islets of the camel, horse and cattle. Eur J Anat 19:27-35.

14. Helmstaedter V, Feurle GE, Forssmann WG 1976. Insulin, glucagon and somatostatin-immuno-reactive endocrine cells in the equine pancreas. Cell Tissue Res 172: 447-454.
15. Hiratsuka T, Abe M, Takehana K, Iwasa K, Hiraga T, Kobayashi A. 1996. Immunohistochemical analysis of the endocrine cells in the pancreatic islets of cattle. Okajimas Folia Anat Jpn 72: 285-295. doi: 10.2535/ofaj1936.72.6_285

16. Ito S, Yamada Y, Hayashi M, Matsubara Y. 1978. Somatostatin containing cells in the rat and horse pancreatic islets. Tohoku J Exp Med 124: 57-64.

17. Khatim MS, Gumaa KA, Petersson B, Lundqvist $G$, Grimelius $L$, Hellerström. 1985. The structure and hormone content of the endocrine pancreas of the one humped camel (Camelus dromedarius). Anat Anz 159: 181-186.

18. Kim A, Miller K, Jo J, Kilimnik G, Wojcik P, Hara M. 2009. Islet architecture: a comparative study. Islets 1: 129-136. doi: 10.4161/isl.1.2.948

19. Mansouri SH, Gholami S, Mousavi GH. 2006. Histomorphometrical study of pancreas in Mehraban female sheep. Iran J Vet Res 7: 14-19. doi: 10.22099/ ijvr.2006.2658

20. Montanya E, Nacher V, Biarnés $M$, Soler J. 2000. Linear correlation between beta-cell mass and body weight throughout the lifespan in Lewis rats: role of beta-cell hyperplasia and hypertrophy. Diabetes 49: 1341-1346.

21. Muranishi T, Takehana K, Hiratsuka T, Kobayashi A, Eerdunchaolu, Iwasa K, Abe M. 1999. An investigation of the relationship between duct system and A cell-rich and $\mathrm{PP}$ cell-rich pancreatic islets in the canine pancreas. J Vet Med Sci 61: 737-742.

22. Navarrete M, Sato A. 2010. Aspectos anatómicos de la cría de alpaca. En: Sanidad de alpacas en la etapa neonatal. Manual para estudiantes y profesionales de veterinaria. España: Univ Complutense. p 51-62.

23. Panesi G 2016. Estudio morfológico del páncreas en alpacas (Vicugna pacos) jóvenes y adultas. Tesis de Médico Veterinario. Lima: Univ Nacional Mayor de San Marcos. 28 p. 
24. Quispe EC, Rodriguez TC, Iñiguez LR, Mueller JP. 2009. Producción de fibra de alpaca, llama, vicuña y guanaco en Sudamérica. Anim Genet Resources Information 45: 1-14.

25. Reddy S, Elliot R. 1985. Insulin, glucagon, pancreatic polypeptide hormone and somatostatin in the goat pancreas: demonstration by immunocytochemistry. Aust J Biol Sci 38: 59-66.

26. Reddy S, Bibby NJ, Elliott RB. 1988. An immunofluorescent study of insulin-, glucagon-, pancreatic polypeptideand somatostatin-containing cells in the early ovine fetal pancreas. Q J Exp Physiol 73: 225-232. doi: 10.1113/expphysiol.1988.sp003135

27. Steiner DJ, Kim A, Miller K, Hara M. 2010. Pancreatic islet plasticity: interspecies comparison of islet architecture and composition. Islets 2: 135-145. doi: 10.4161/is1.2.3.11815

28. Wang H1, Maechler P, Ritz-Laser B, Hagenfeldt KA, Ishihara H, Philippe J, Wollheim CB. 2001. Pdx1 level defines pancreatic gene expression pattern and cell lineage differentiation. J Biol Chem 276: 25279-252786. doi: 10.1074/ jbc.M101233200
29. Wang X, Zielinski MC, Misawa R, Wen P, Wang TY, Wang CZ, Witkowski P, Hara M. 2013. Quantitative analysis of pancreatic polypeptide cell distribution in the human pancreas. PLoS One 8(1): e55501. doi: 10.1371/journal.pone.0055501

30. Yang C, David M, Wang Z, Stoll B, Lackeyram D, Swanson KC, Yin Y, et al. 2011. Apical $\mathrm{Na}+-\mathrm{D}$-glucose cotransporter 1 (SGLT1) activity and protein abundance are expressed along the jejunal crypt-villus axis in the neonatal pig. Am J Physiol Gastrointest Liver Physiol 300: G60-G70. doi: 10.1152/ ajpgi.00208.2010

31. Zanuzzi C. 2010. Efectos de la intoxicación con Solanum glaucophyllum (duraznillo blanco) sobre la proliferación, diferenciación y muerte celular en el intestino de conejos. Tesis de Doctorado. Argentina: Univ Nacional de La Plata. $286 \mathrm{p}$.

32. Zghair FS. 2016. Immunofluorescence identification of the endocrine cells in the pancreatic islets of the camel (Camelus dromedarius). Kufa J Vet Med Sci 7(1): 138-146. 